\title{
Vascular Pericyte Density and Angiogenesis Associated with Adenocarcinoma of the Prostate
}

\author{
Murray C. Killingsworth ${ }^{\mathrm{a}-\mathrm{c}}$ Xiaojuan $\mathrm{Wu}^{\mathrm{a}, \mathrm{c}}$ \\ ${ }^{a}$ Department of Anatomical Pathology, South Western Area Pathology Service, ${ }^{b}$ Faculty of Medicine, \\ University of New South Wales, and 'School of Medicine, University of Western Sydney, Sydney, N.S.W., Australia
}

\section{Key Words}

Adenocarcinoma · Angiogenesis $\cdot$ Pericyte $\cdot$ Prostate

\begin{abstract}
Background/Aims: Angiogenesis facilitates metabolism, proliferation and metastasis of adenocarcinoma cells in the prostate, as without the development of new vasculature tumor growth cannot be sustained. However, angiogenesis is variable with the well-known phenomenon of vascular 'hotspots' seen associated with viable tumor cell mass. With the recent recognition of pericytes as molecular regulators of angiogenesis, we have examined the interaction of these cells in actively growing new vessels. Methods: Pericyte interactions with developing new vessels were examined using transmission electron microscopy. Pericyte distribution was mapped from $\alpha$-SMA+ immunostained histological sections and quantified using image analysis. Data was obtained from peripheral and more central regions of 27 cases with Gleason scores of 4-9. Results: Pericyte numbers were increased around developing new vessel sprouts at sites of luminal maturation. Numbers were reduced around the actively growing tips of migrating endothelial cells and functional new vessels. Tumor regions internal to a $500-\mu \mathrm{m}$ peripheral band showed higher microvessel pericyte density than the peripheral region. Conclusion: Pericytes were found to be
\end{abstract}

key cellular components of developing new vessels in adenocarcinoma of the prostate. Their numbers increased at sites of luminal maturation with these cells displaying an activated phenotype different to quiescent pericytes. Increased pericyte density was found internal to the peripheral region, suggesting more mature vessels lie more centrally.

Copyright $\odot 2011$ S. Karger AG, Basel

\section{Introduction}

Interaction of endothelial cells and pericytes is fundamental to tumor new vessel formation in adenocarcinoma of the prostate ( $\mathrm{PCa}$ ) with pericytes increasingly being recognized as providing molecular regulation of angiogenesis $[1,2]$. The importance of angiogenesis to the behavior and progression of PCa has been emphasized by studies showing correlation of increased vascular density with advanced tumor stage [3], metastasis [4], expression of the angiogenic factors VEGF and bFGF with the receptors FLK/KDR and Flt-1 [5] and poor outcome $[6,7]$. However, despite these advances there remains a large subset of cases with intermediate Gleason scores for whom prognosis is uncertain [8], indicating that more sensitive biomarkers of tumor behavior are still required.

\section{KARGER}

Fax +41613061234

E-Mail karger@karger.ch

www.karger.com
(C) 2011 S. Karger AG, Basel

$1015-2008 / 11 / 0781-0024 \$ 38.00 / 0$

Accessible online at:

www.karger.com/pat
Assoc. Prof. Murray Killingsworth, $\mathrm{PhD}$

Department of Anatomical Pathology

South Western Area Pathology Service, Locked Bag 7090

Sydney, NSW 1871 (Australia)

Tel. +61 29828 5392, Fax +61 29828 5328, E-Mail m.killingsworth@unsw.edu.au 
Development of new tumor vasculature is dependent on many factors including stimulation and inhibition signalling from both tumor cells and host response cells such as macrophages and other chronic inflammatory cells [3, 9]. Angiogenic signalling from tumor cells may in turn be modulated by dynamics including cell viability, differentiation, apoptosis and necrosis. Microenvironmental factors such as stromal matrix deposition, proximity to the stromal-epitheilial interface [3] and hypoxia [10,11] may also influence the induction of angiogenesis.

It is not well understood how the level of angiogenesis is regulated in different regions of prostatic tumors or what regional variation might exist in different tumor phenotypes. Tumor vasculature is generally characterized by increased blood flow in the periphery with reduced flow in necrotic central regions [12] but variation in the angiogenic response may also occur throughout the viable tumor cell mass, as indicated by the phenomenon of vascular 'hotspots' [4]. As many studies of tumor angiogenesis have relied on single endothelial cell biomarkers to establish microvessel density (MVD), the role of other modulators such as pericytes is less well understood. We have therefore investigated the interaction and distribution of pericytes with developing tumor new vessels in a series of PCa tumors with the aim of understanding the relationship of angiogenesis to tumor progression.

\section{Materials and Methods}

This study is based on examination of radical prostatectomy specimens from 27 patients diagnosed with adenocarcinoma of the prostate by routine histopathological examination. Gleason scores ranged from 4 (low-grade malignancy) to 9 (high-grade malignancy).

Prostate specimens fixed in buffered formalin were marked with ink prior to dissection to provide orientation. The complete organ was then dissected into horizontal slices approximately $2 \mathrm{~mm}$ thick with nicks placed at the tissue margins to maintain orientation after processing. A detailed diagram was produced for each case with tissue slices and block numbers recorded along with any areas suspected of containing adenocarcinoma identified. Tissue slices suspected of containing adenocarcinoma were then processed to paraffin blocks with the remainder held in formalin. Case examination and reporting was routine and performed by a histopathologist. After the final report was issued, paraffin blocks found to contain adenocarcinoma were selected for inclusion in this study and adjacent tissue stored in formalin sampled for electron microscopy.

For immunohistochemistry, antigen retrieval was carried out using either microwave irradiation (650 Watt) with $10 \mathrm{mM}$ citrate buffer ( $\mathrm{pH} 6.0$ ) at $95^{\circ} \mathrm{C}$ or proteolytic enzyme digestion. Immunostaining was routine using an auto-immunostainer (Dako). All slides were incubated in primary antibody at room temperature followed by application of a biotinylated secondary antibody (Dako) followed by peroxidase-labelled streptavidin (Dako), diaminobenzedine (Sigma No. D-5637) and counterstaining with Harris haematoxylin. Positive controls and a negative control with primary antibody omitted were run with each staining run. Tumor glands were identified using high molecular weight cytokeratin (HMWK Clone 34BE12; Dako Corporation) to distinguish acinar structures lacking HMWK+ basal cells [13]. Tissue microvessels including mainly capillaries and small venules with occasional arterioles were identified with the universal endothelial cell marker CD31 (Clone JC/70A; Dako). Pericytes were identified using $\alpha$-smooth muscle actin ( $\alpha$-SMA, Clone 1A4; Dako). Primary antibody concentrations were determined through a series of dilutions with selection criteria including the intensity of positive staining and absence of non-specific background staining. The following dilutions were used: CD31 (1:50), $\alpha$-SMA (1:100) and HMWK (1:75). From these test runs a suitable positive control was selected. This control was used to monitor batch variation and as a reference for determining intensity of staining in each test.

Vascular mapping was performed using color-recognition segmentation algorithms in a computer-based image analysis system. Images for microvessel area (MVA) and microvessel pericyte density (MPD) assessment were acquired from vascular hotspots as described by Weidner et al. [14] from the tumor periphery, tumor central region and normal benign tissue for each case. For the purposes of this study, the peripheral zone was identified as being within $500 \mu \mathrm{m}$ from the tumor margin. All other tumor tissue was classified as central. Single high-resolution 24-bit uncompressed $1,600 \times 1,200$ pixel RGB colour digital TIFF format images (SPOT RT Slider; Diagnostic Instruments Inc.,) were acquired from each region using a $20 \times$ objective. This magnification corresponds to the $\times 200$ magnification used for visual MVD assessment by others $[4,14,15]$, but the imaged area of $0.15 \mathrm{~mm}^{2}$ is smaller than quoted for some other visual surveys. Commercial image analysis software was used (Image-Pro Plus; Media Cybernetics) employing color recognition to quantify the diaminobenzidine chromogen indicating positive immunostaining. MVA was calculated by quantification of CD31+ immunostaining using an automated segmentation routine that included setting image brightness and contrast to standard levels, sharpening and vessel hole filling to include the vessel luminal area. Images were segmented into three colors corresponding to vascular area, other tissue and luminal open space. Some manual adjustment of segmentation was performed prior to collection of measurement data. MVA scores were expressed as a percentage of the total image area and were corrected for luminal open space as in previous studies $[16,17]$. Pericyte density was assessed by segmentation of $\alpha$-SMA+ cells associated with vascular structures. The MPD score was derived from the area of $\alpha$-SMA+ cells expressed as a percentage of total tissue area. Scores were obtained using the same macroprogram as for the CD31 studies except with the hole-filling function omitted.

Cases were grouped into several categories for assessment with mean scores from each group tested for significance using ANOVA $(p<0.05)$. Based on the pathological stage of the tumor [18], two groups were defined. The stage 1 tumor group included cases with organ-confined disease (pT2) and the stage 2 tumor group included cases with extraprostatic extension (pT3) or evidence of metastatic disease (pT4). Two tumor grade groups were used. Gleason group 1 included cases with Gleason scores of 4-6 and Gleason group 2 included cases with Gleason scores of 7-9. 


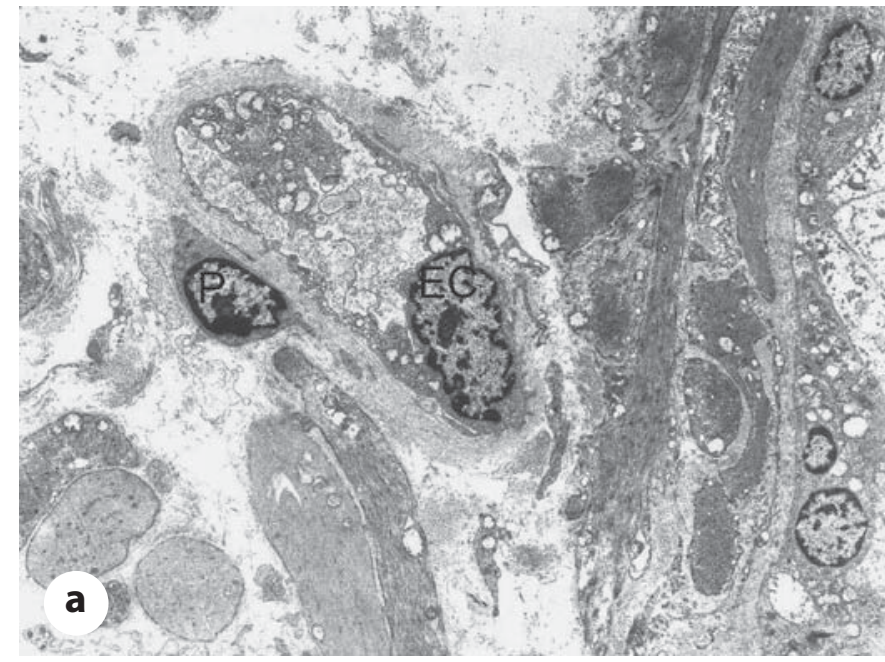

Fig. 1. Low-power electron microscopy showing normal preexisting vessels in close proximity to glandular epithelial cells. a Capillary with typical rounded outline showing mature endothelial cells (EC) and pericyte (P) embedded in the basement membrane. b Larger capillary with rounded outline showing a pericyte with condensed cytoplasm and cell processes extending around the vessel basement membrane. Glandular epithelial cells on left hand side. c Vessel with elongated outline closely apposed to the glandular epithelium.

Transmission electron microscopy specimens were obtained using a 2-mm punch biopsy and sampling from formalin-fixed tissue slices. Tissue processing was routine and included fixation in $2.5 \%$ glutaraldehyde in $0.1 \mathrm{M}$ sodium cacodylate buffer $\mathrm{pH} 7.4$ followed by staining with osmium tetroxide $2 \%$ and uranyl acetate $2 \%$ then embedding in Spurr low viscosity resin. Sections were cut at $120 \mathrm{~nm}$ and examined with a Morgagni 268D transmission electron microscope (FEI) at $80 \mathrm{kV}$. Images were acquired using an integrated MegaView II digital camera (Soft Imaging System $\mathrm{GmbH}$ ). Seven of 27 cases included in this study were examined by electron microscopy.

Patient consent was given for routine examination of surgical tissue for all cases reported in this study. The images and analysis described were obtained from specimens used for routine investigations carried out as part of the normal diagnostic process. Ethics approval for the project was obtained from the Sydney South West Area Health Service Human Research Ethics Committee (QA2010/006).
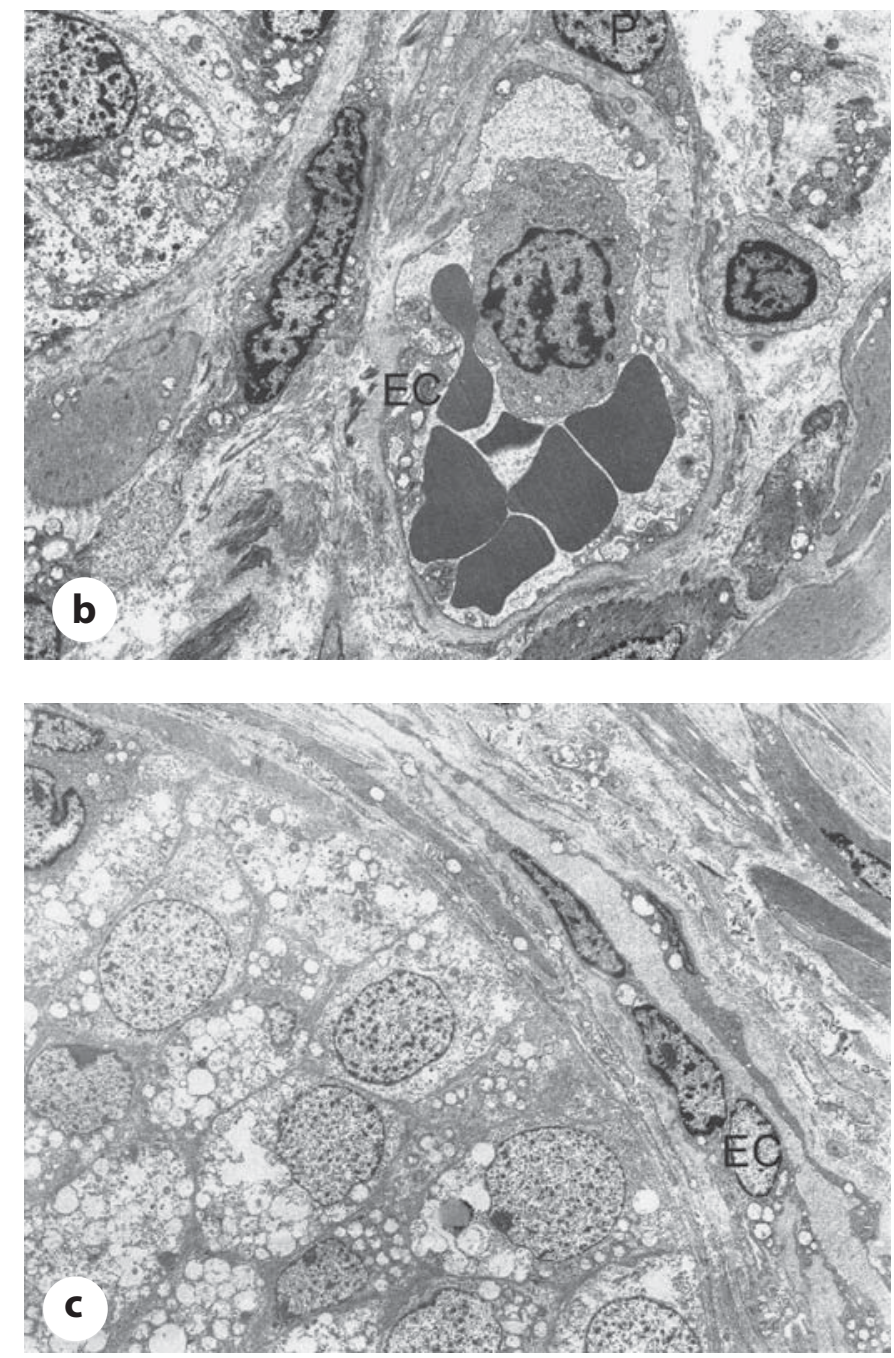

\section{Results}

A preliminary investigation of normal benign microvessels and tumor new vessels by electron microscopy was undertaken to investigate the association of pericytes with developing tumor new vessels. Pre-existing capillaries and venules of normal or benign hyperplastic tissue were identified close to glandular cell formations and possessed a regular rounded to elongated profile (fig. 1). Endothelial cells and pericytes forming these vessels showed condensed cytoplasm and were surrounded by uniform basement membrane. Tumor new vessels, on the other hand, typically possessed an irregular outline and followed a tortuous course in the tissue often containing regions of endothelial cells and pericytes with dilated and watery cytoplasm (fig. 2) suggestive of an immature phenotype. 
Fig. 2. Electron microscopy showing interaction of endothelial cells (EC) and pericytes $(\mathrm{P})$ in developing tumor new vessels. a Endothelial cell buds and filopodia (arrows) extending into the surrounding matrix. b Endothelial cell showing change in polarity with the nucleus (arrow) moving away from the lumen (L). c Cross-section through an endothelial cell sprout (outlined) with slit-like lumen (arrowhead). d Larger endothelial cell sprout (outlined) with a slit-like lumen (arrowhead) and enlarged activated pericytes. e Activated pericytes in close contact and engulfing filopodia (arrow) of activated endothelial cells. f Maturing new vessel completely surrounded by activated pericytes.
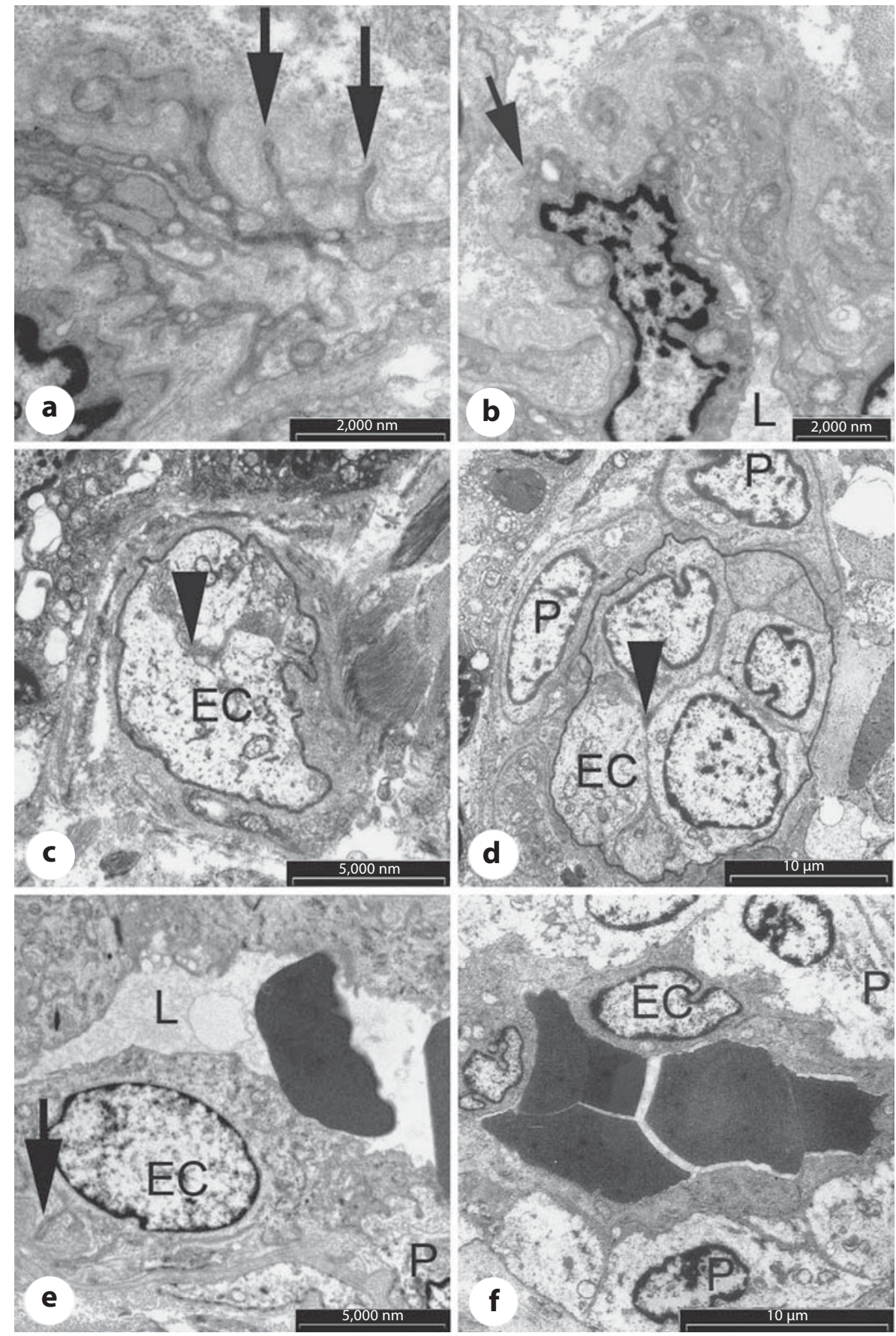

The earliest morphological change detected in capillaries and small venules consistent with angiogenic activation was the extension of slender cell processes and filopodia from endothelial cells through the vascular basement membrane into the surrounding stroma. Extension of filopodia was occasionally accompanied by changes in cell polarity in the vessel wall (fig. 2). Endothelial cell sprouts were recognizable by their slit-like lumen lying between closely apposed endothelial cells. Tip cells of these structures displayed condensed cytoplasm and extensive cell processes protruding into surrounding thick basement membrane-like material. Distal to the tip, endothelial sprouts comprised regions of endothelial cells with watery cytoplasm and rounded nuclei. As the lumen 


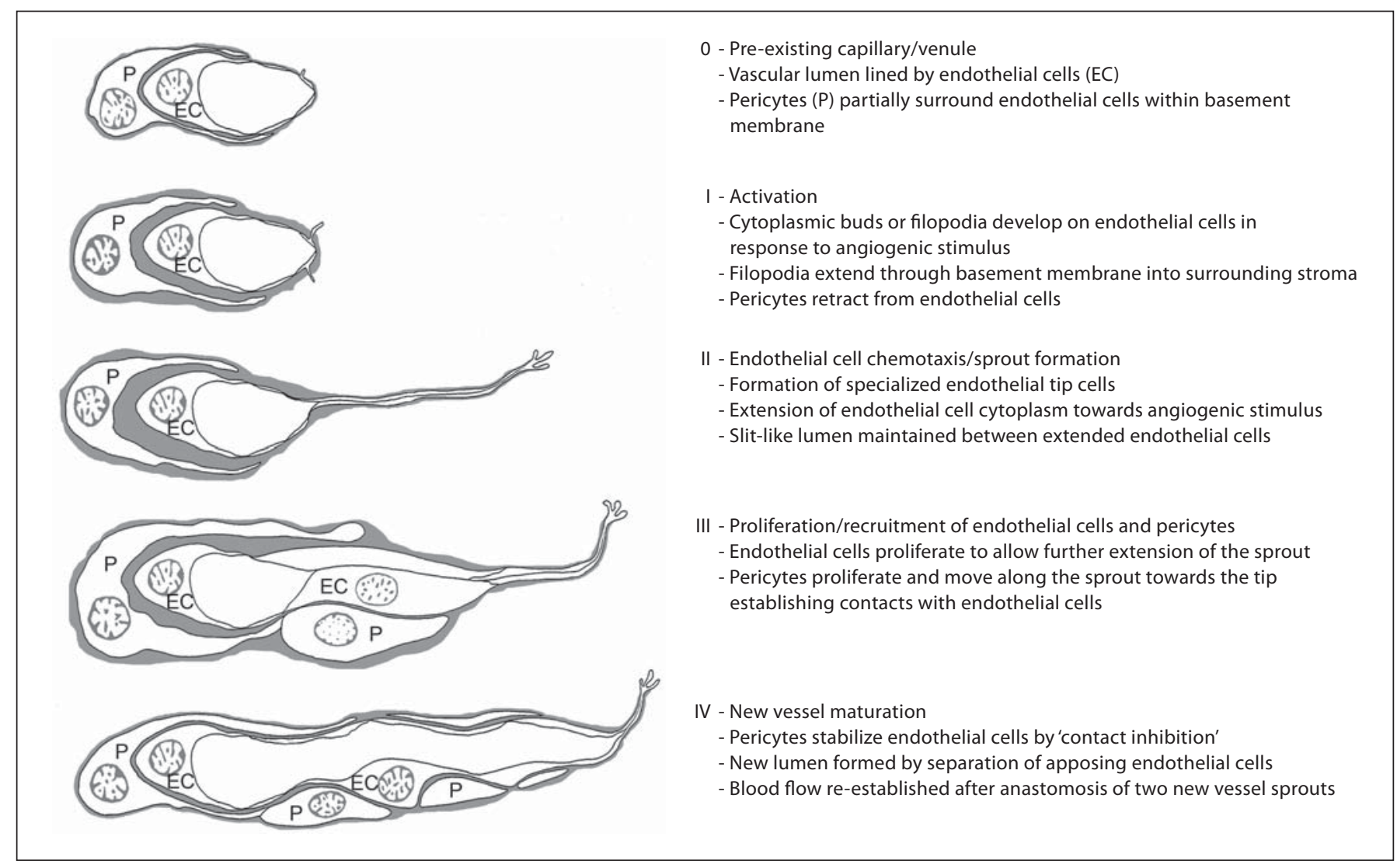

Fig. 3. Diagram depicting interactions of endothelial cells (EC) and pericytes $(\mathrm{P})$ in formation of tumor new vessels.

widened the endothelial cell cytoplasm appeared more differentiated and increased numbers of pericytes were observed, presumably representing progressive maturation of the vessel. Mature tumor new vessels with a patent lumen were bordered by endothelial cells with elongated to round nuclei and condensed cytoplasm.

Pericytes associated with tumor new vessels (fig. 2) displayed phenotypic changes from their quiescent counterparts in normal benign tissue. Whereas resting normal cells possessed condensed cytoplasm, nuclei with condensed chromatin and characteristic subplasmalemma densifications (fig. 1), those associated with developing endothelial cell tubes were enlarged with dilated cytoplasm and possessed nuclei with centrally dispersed chromatin and subplasmalemma densifications, but were separated from neighboring endothelial cells by thickened basement membrane (fig. 2). Maturation of new endothelial cell sprouts indicated by widening of the lumen was associated with pericytes moving to closer contact with endothelial cells and thinning of the intercellular basement membrane. In some cases, pericytes completely encircled developing vessels indenting the endothelial cell outer membrane (fig. 2).

Based on our ultrastructural observations we have proposed a sequence of events for angiogenesis leading from activation of pre-existing vessels through to formation of new tumor vessels (fig. 3). We identified a flare of pericyte density associated with developing endothelial cell sprouts, so we would expect increased pericyte density to indicate regions of active new vessel growth. To visualize variation in cell density across tumor regions and tumor stages we have developed a mapping protocol based on color recognition of positive immunostaining (figs. 4 and 5). These density maps are produced from light micrographs taken at $\times 20$ to give a wider view than is possible with electron microscopy. Areas of positive immunostaining were then quantified using routine image analysis color-recognition algorithms.

MVA scores were based on quantification of the endothelial cell marker anti-CD31. MVA scores from tumor 


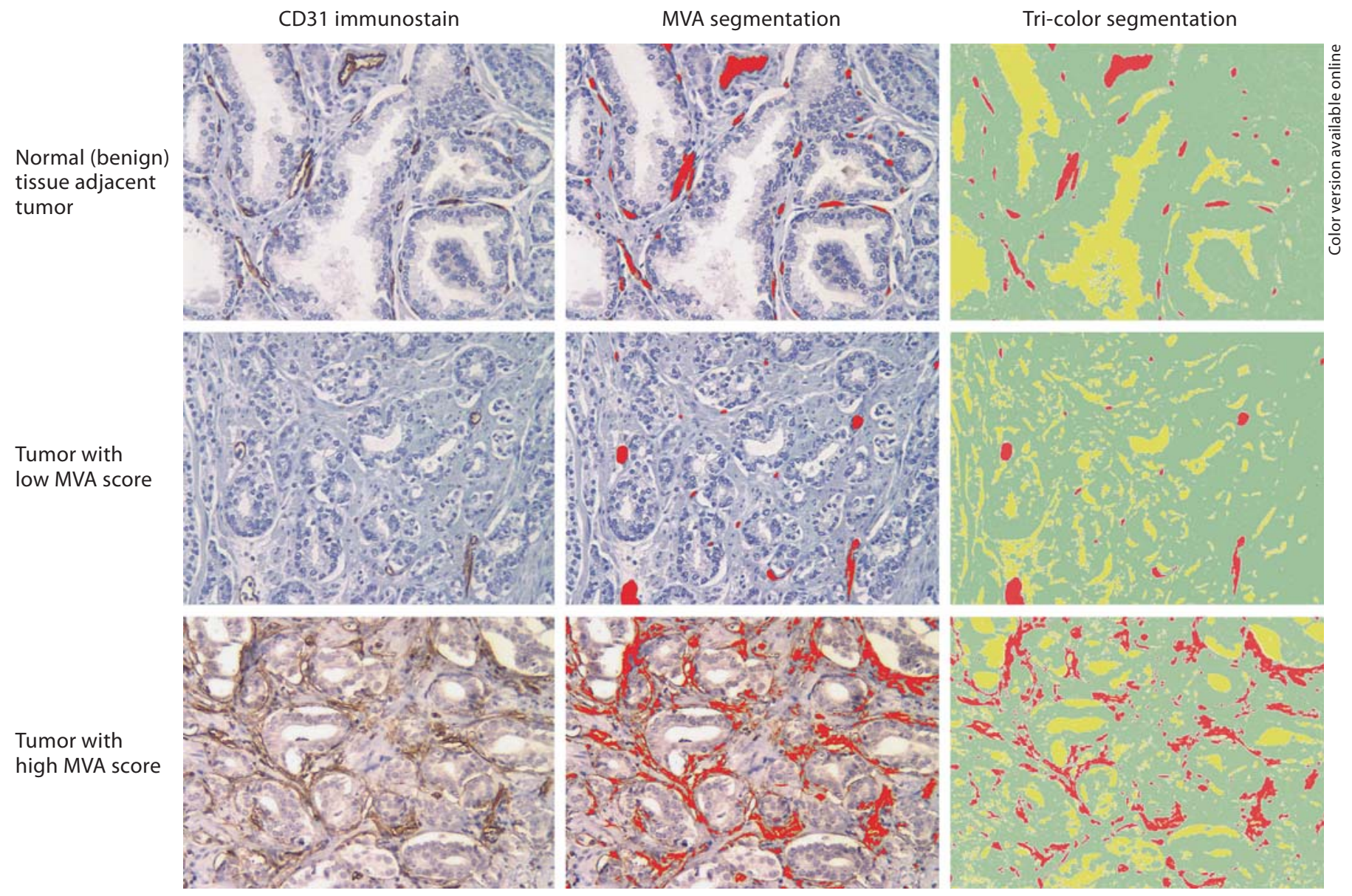

Fig. 4. Range of cases showing MVA scores determined from image analysis of CD $31+$ vessels $(\times 20$ objective). The score is based on the percentage of immunostained MVA to total tissue area. Scores were corrected for luminal open space.

central and peripheral regions from either tumor stage group $(\mathrm{n}=27)$ were higher than from normal regions (fig. 6a) with tumor central regions being significantly higher $(p=0.0238)$. Analysis of tumor stage groups showed group $2(\mathrm{n}=13)$ to have higher scores than normal regions (fig. 6b) with tumor central regions significantly higher than normal regions and tumor edge scores from group 1 $(\mathrm{p}=0.0016)$. Analysis of MVA scores compared with Gleason score (fig. 6c) showed Gleason group 2 to have higher mean scores than Gleason goup 1, particularly in central regions, but when tested there was no significant difference between groups probably due to low sample size.

MPD scores were based on quantification of anti- $\alpha$ SMA immunostaining of perivascular cells. MPD scores from central and peripheral regions in either tumor stage group $(\mathrm{n}=27)$ were higher than for normal tissue (fig. $6 \mathrm{~d}$ ) with tumor central scores significantly higher than nor- mal tissue scores $(\mathrm{p}=0.0187)$. Tumor stage group $2(\mathrm{n}=$ 13) had higher scores than normal regions (fig. 6e) with tumor central and peripheral regions significantly higher than normal regions $(p=0.0001)$. Furthermore, tumor central regions from group 2 were significantly higher than scores from either region in group $1(\mathrm{p}=0.0001)$. Gleason group 2 tumor scores (fig. 6f) were higher than Gleason group 1 tumor scores. Gleason group 2 tumor central regions were significantly higher than either region of Gleason group $1(\mathrm{p}=0.0006)$.

\section{Discussion}

Progressive growth and expansion of adenocarcinoma in the prostate requires efficient angiogenesis involving interaction of both endothelial cells and pericytes. Until 


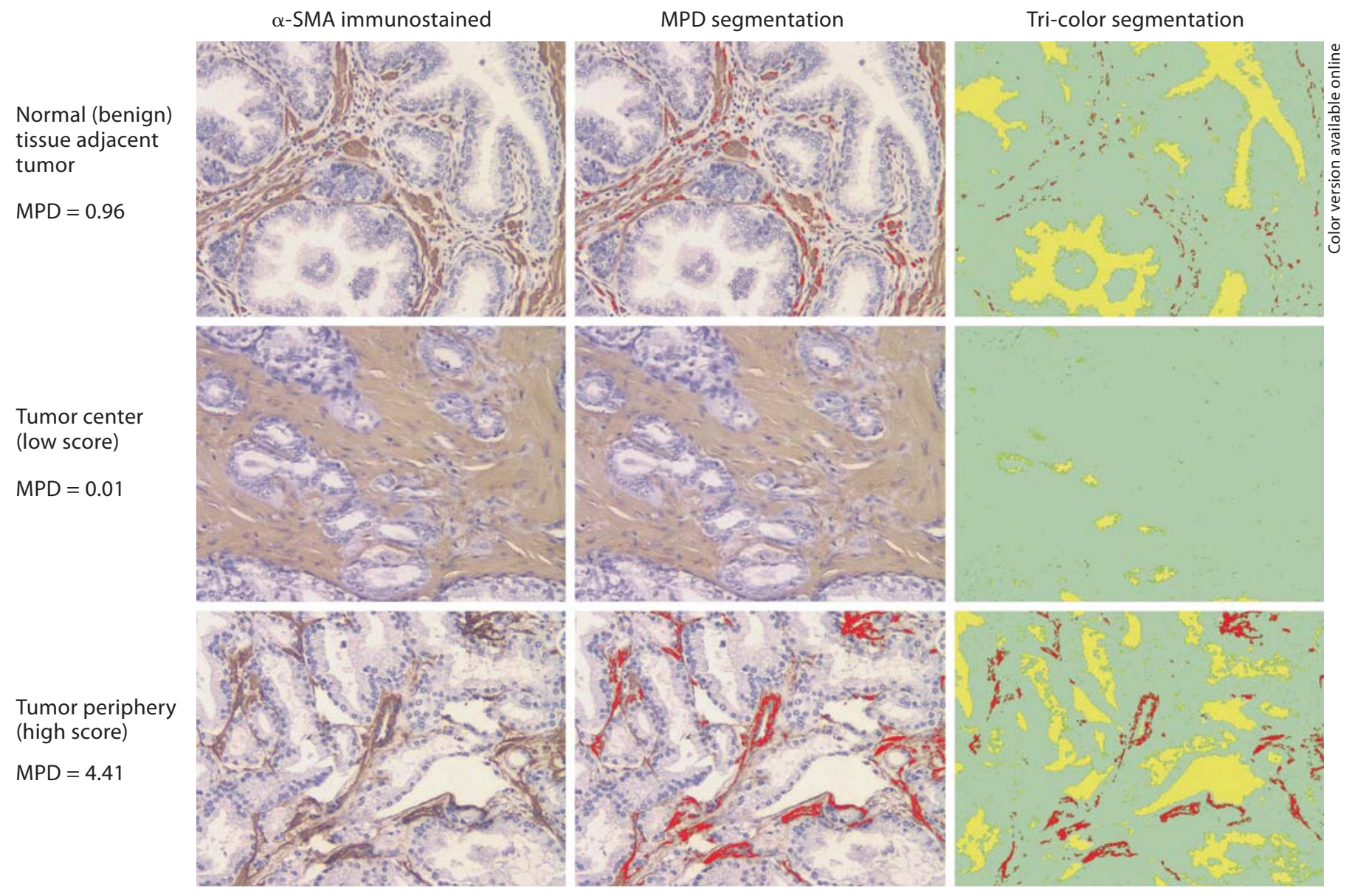

Fig. 5. Range of cases showing range of MPD scores determined from image analysis of $\alpha$-SMA+ cells surrounding vessels ( $\times 20$ objective). The score is based on the percentage of area of immunostained pericytes to total tissue area. Scores were corrected for luminal open space.

recently it had been unclear how to interpret pericyte numbers associated with angiogenesis. However, their role in the molecular regulation of new vessel maturation is now being increasingly recognized $[2,19]$.

In this study we have examined the interaction of endothelial cells and pericytes by electron microscopy in both quiescent pre-existing vessels and actively growing new vessels in PCa. We have identified several morphological features that characterized active angiogenesis.

Angiogenesis appeared to be initiated in the endothelial cells forming capillaries and small venules. Extension of small cytoplasmic buds and filopodia through the vessel basement membrane into the surrounding stroma were the first detectable change. These structures have been described previously [20] and are thought to represent the first growth response towards an angiogenic stimulus. Changes in endothelial cell polarity and the formation of endothelial cell sprouts or tubes were also evident. These structures indicate endothelial cell chemotaxis and proliferation leading to extension of the capillary tube towards an angiogenic stimulus. Distal to the leading tip cells these slender vascular extensions were identified by the presence of immature endothelial cells with 'watery' cytoplasm bordering a slit-like lumen and accompanied by sparse pericytes. Pericyte-like cells were also observed near endothelial cell sprouts in the surrounding stroma. Pericytes had been observed in various pathological processes in advance of endothelial sprouts appearing to guide or precede endothelial cell migration [21-23] possibly by producing VEGF [24]; however, in general rapid endothelial cell extension at the new vessel tip takes place with few accompanying pericytes.

Developing new vessel sprouts were readily recognizable by the presence of a slit-like lumen between imma- 


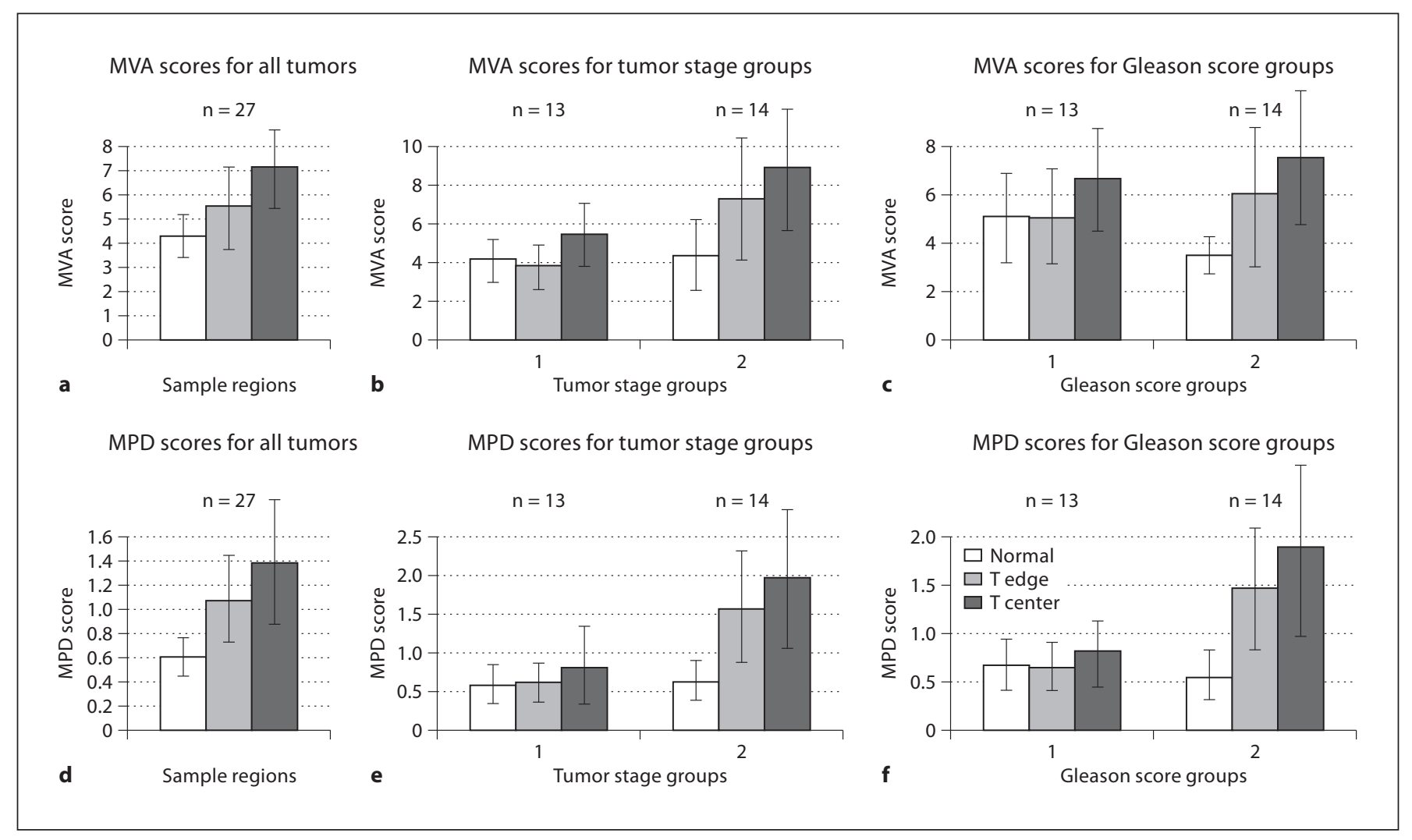

Fig. 6. Charts showing summary results for quantification of MVA (a-c) and MPD (d-f). Error bars indicate $95 \%$ confidence intervals.

ture endothelial cells and often the incorporation of increased numbers of pericytes in the vessel wall. These pericyes displayed an activated phenotype characterized by extensive cytoplasm and numerous cell contacts with endothelial cells. Their presence appeared to represent a burst of activity around maturing new vessel sprouts related to a phase of vessel maturation, remodeling and vascular basement membrane matrix assembly $[22,25]$ taking place distal to the advancing tip.

Maturation of endothelial cell sprouts to patent new vessels was characterized by progressive widening of the lumen and ultimately the presence of red blood cells indicating anastamosis was completed and blood flow had been established. Fully mature and functional new capillaries generally showed an irregular profile following a tortuous course through the stroma with few surrounding pericytes evident.

Pericytes now appear to be central to tumor new vessel formation, regarded as mesodermal progenitors that may differentiate into a wide variety of cell types including mesenchymal stem cells $[26,27]$ or cells with mesenchy- mal capacity [28]. Pericytes associated with actively growing new vessels possessed an activated ultrastructural phenotype that differed from their resting counterparts of quiescent vessels. Their features were more suggestive of migratory function with less differentiated cytoplasmic components and filaments. The immunohistochemical features of activated pericytes also differs with NG2 expression reported [29] and upregulated $\alpha$ SMA expression mediated by TGF- $\beta 1$ [30]. Some activated pericytes appear to be derived from PDGFR $\beta+$ progenitor perivascular cells recruited from the bone marrow while others are derived from pre-existing activated cells [31]. Activation of pericytes, their proliferation and migration therefore appear to be essential attributes of angiogenesis and overexpression of PDGF-BB in tumors results in increased pericyte coverage of vessels [32]. Indeed, targeting of pericytes in addition to endothelial cells with antiangiogenic therapy was found to be more efficacious in disrupting vasculature than either single agent in a mouse tumor model [33]. Inhibition of VEGF and its receptor can lead to pericyte activation and vessel 
maturation [34], and the level of vessel maturation indicated by coverage of mature pericytes is associated with resistance to anti-angiogenic therapy $[35,36]$. Neutralizing antibody to pericyte-NG2 decreased neovascularization and lymphangiogenesis in an experimental model based on implanted human and mouse transgenic prostate cancer cells [37], and agents that target EGFR such as gefitinib may decrease the coverage of small vessels by pericytes [38].

Density mapping of microvessels is a convenient way to visualize positive immunostaining of endothelial cells and pericytes that allows quantification using image analysis techniques. Analysis of MVA data confirmed increasing scores with tumor formation, stage and Gleason score. This was not surprising as MVA is a measure of vascular density as is MVD scoring, shown in many previous studies to increase in tumor formation and progression $[3,4,39]$. Interestingly, in the present study peripheral regions of PCa showed lower MVA scores than more central regions. This result was unexpected from experimental studies of blood flow in transplanted fibrosarcoma that have demonstrated higher flow in the peripheral tumor zone [12], but was in agreement with another study of PCa which showed a stepwise increase in MVD toward the center of the neoplasm [40]. Our results may be explained by the fact that MVA assessment assigns different weights to larger caliber vessels and may therefore reflect the presence of larger caliber vessels located more centrally in PCa tumors.

Assessment of pericyte numbers by a similar density mapping technique also revealed scores to be higher in central regions than peripheral regions of PCa tumors. Group 1 tumor MPD scores were not significantly higher than adjacent normal benign tissue. This finding suggests that the 'angiogenic switch' [41-43] or up-regulation of angiogenesis may not be activated in peripheral regions. Group 2 tumors showed significantly higher scores than group 1 and increasing Gleason grade also showed higher scores. Increased numbers of pericytes in tumors compared to normal tissue have been reported previously [44], but the present data appear to be the first evidence of higher numbers of pericytes in more advanced tumor stages.

Our data support the hypothesis that a zone of maturing vessels lies internal to a less vascularized peripheral region. This has implications for sampling and the use of MVD histological scoring for prognosis and emphasizes the need to fully understand regional variation in the level of angiogenesis. We speculate that new tumor growth in the periphery may provide a chemotactic stimulus to angiogenesis and as a result the developing new vessels in this zone may be more in the sprouting phase than the luminal maturation phase of development. The lesser diameter of endothelial cell sprouts and tubes would produce a lower MVA score than the more mature microvessels lying internally. By contrast the higher scores seen more centrally may be explained by the presence of relatively larger caliber, more established vessels.

Pericytes have been regarded as difficult to define [45], the lack of a specific immunochemical marker [46] supports the role of using electron microscopy to umambiguously identify pericytes [47]. However, in addition to electron microscopy, we have used anti- $\alpha$-SMA to survey the distribution and density of pericytes. This antibody is considered an acceptable marker for pericytes associated with angiogenesis in granulation tissue associated with wound healing, synovitis [48] and neovascularization [44]. However, it has been reported that $\alpha$-SMA may fail to stain pericytes of normal capillaries $[29,44]$ and growing capillaries in a rodent model of tumor angiogenesis [23]. We therefore investigated $\alpha$-SMA staining of resting pericytes in normal benign prostatic tissue and indeed found $\alpha$-SMA+ cells surrounding pre-existing microvessels. Some debate also still exists as to whether $\alpha$-SMA is an acceptable antibody for the identification of activated pericytes [21,23]. We believe, on the basis of our ultrastructural studies, that with careful antigen retrieval $\alpha$-SMA+ staining is a suitable method to identify resting and activated pericytes in PCa. Non-specific $\alpha$-SMA+ staining of myofibroblasts and stromal smooth muscle cells has also been reported. To address this, our image analysis segmentation was adjusted to gate out cells remote from vessels. This process was aided by the less intense staining of stromal cells compared to vascular pericytes.

The role of pericytes in the modulation of endothelial cell growth by contact inhibition [49] initially suggested that angiogenesis might be dampened by their presence. The opposite now seems to be true with high numbers thought to be indicative of enhanced angiogenesis by assisting with the formation of functional endothelial cell vessels leading to more successful vascularization $[1,31]$. Our MPD data suggest that the level of angiogenesis in stage 1 tumors is not significantly higher than that of normal benign tissue and that stage 2 tumors show significant increase in the level of angiogenesis. The zone of maximal pericyte density, probably corresponding to the site of vessel maturation, is not the surface zone but lies deeper within the tumor mass. 
Data derived from analysis of pericyte proliferation and migration as well as other parameters such as microvessel shape, endothelial cell proliferation and migration, and the development of perivascular stroma could give a more complete view of the rate and quality of angiogenesis underway and clarify the relationship of tumor growth to vascular supply.

\section{Acknowledgements}

The authors thank Professor David J. Davies and Professor Athol W.J. Lykke for their input on the design of this study and many helpful comments.

\section{References}

${ }_{1}$ Bergers G, Song S: The role of pericytes in blood-vessel formation and maintenance. Neuro Oncol 2005;7:452-464.

-2 Adams RH, Alitalo K: Molendothelial cellular regulation of angiogenesis and lymphangiogenesis. Nat Rev Mol Cell Biol 2007; 8:464-478.

-3 Brawer MK, Deering RE, Brown M, Preston SD, Bigler SA: Predictors of pathologic stage in prostatic carcinoma: the role of neovascularity. Cancer 1994;73:678-687.

4 Weidner N, Carroll PR, Flax J, Blumenfeld W, Folkman J: Tumor angiogenesis correlates with metastasis in invasive prostate carcinoma. Am J Pathol 1993;143:401-409.

5 Pallares J, Rojo F, Iriarte J, Morote J, Armadans LI, de Torres I: Study of microvessel density and the expression of the angiogenic factors VEGF, bFGF and the receptors Flt-1 and FLK-1 in benign, premalignant and malignant prostate tissues. Histol Histopathol 2006;21:857-865.

6 Weidner N: Editorial: Tumoral vascularity as a prognostic factor in cancer patients: the evidence continues to grow. J Pathol 1998; 184:119-122.

7 Concato J, Jain D, Uchio E, Risch H, Li WW, Wells CK: Molecular markers and death from prostate cancer. Ann Intern Med 2009; 150:595-603.

8 Chodak GW, Warren KS: Watchful waiting for prostate cancer: a review article. Prostate Cancer Prostatic Dis 2006;9:25-29.

9 De Marzo AM, Platz EA, Sutcliffe S, Xu J, Gronberg H, Drake CG, Nakai Y, Isaacs WB, Nelson WG: Inflammation in prostate carcinogenesis. Nat Rev Cancer 2007;7:256-269.

10 Sivridis E, Giatromanolaki A, Koukourakis MI: The vascular network of tumors - what is it not for? J Pathol 2003;201:173-180.

-11 Wang Y, Wan C, Deng L, Liu X, Cao X, Gilbert SR, Bouxsein ML, Faugere M, Guldberg RE, Gerstenfeld LC, Haase VH, Johnson RS, Schipani E, Clemens TL: The hypoxia-inducible factor $\alpha$ pathway couples angiogenesis to osteogenesis during skeletal develop ment. J Clin Invest 2007;117:1616-1626.

-12 Tozer GM, Lewis S, Michalowski A, Aber V: The relationship between regional variations in blood flow and histology in a transplanted rat fibrosarcoma. Br J Cancer 1990;61:250257.

Vascular Pericyte Density and Prostate

Cancer
3 Allsbrook WC Jr, Simms WW: Histochemistry of the prostate. Hum Pathol 1992;23: 297-305.

14 Weidner N, Semple JP, Wech WR, Folkman J: Tumor angiogenesis and metastasis - correlation in invasive breast carcinoma. $\mathrm{N}$ Engl J Med 1991;324:1-8.

15 Borre M, Offersen BV, Nerstrom B, Overgaard J: Microvessel density predicts survival in prostate cancer patients subjected to watchful waiting. Br J Cancer 1998;78:940944.

16 Wakui S, Furusato M, Itoh T, Sasaki H, Akiyama A, Kinoshita I, Asano K, Tokuda T, Aizawa S, Ushigome S: Rapid communication: tumor angiogenesis in prostatic carcinoma with and without bone marrow metastasis: a morphometric study. J Pathol 1992; 168:257-262.

17 Sharma S, Sharma MC, Sarkar C: Morphology of angiogenesis in human cancer: a conceptual overview, histoprognostic perspective and significance of neoangiogenesis. Histopathology 2005:46:481-489.

18 American Joint Committee on Cancer: Prostate; in Greene FL, Page DL, Fleming ID, Fritz AG, Balch CM, Haller DG, Morrow M (eds): AJCC Cancer Staging Manual, ed 6. Berlin, Springer, 2002, pp 309-313.

19 Jain RK: Molecular regulation of vessel maturation. Nat Med 2003;9:685-693.

20 Ausprunk DH, Folkman J: Migration and proliferation of endothelial cells in preformed and newly formed blood vessels during tumor angiogenesis. Microvasc Res 1977; 14:53-65.

21 Nehls V, Denzer K, Drenckhahn D: Pericyte involvement in capillary sprouting during angiogenesis in situ. Cell Tissue Res 1992; 270:469-474

22 Killingsworth MC: Angiogenesis in early choroidal neovascularization secondary to age-related macular degeneration. Graefes Arch Clin Exp Ophthalmol 1995;233:313323.

23 Ozerdem U, Stallcup WB: Early contribution of pericytes to angiogenic sprouting and tube formation. Angiogenesis 2003;6:241249.

24 Reynolds LP, Grazul-Bilska AT, Redmer DA: Angiogenesis in the corpus luteum. Endocrine 2000;12:1-9.
25 Stratman AN, Malotte KM, Mahan RD, Davis MJ, Davis GE: Pericyte recruitment during vasculogenic tube assembly stimulates endothelial basement membrane matrix formation. Blood 2009;114:5091-5101.

26 Chen CW, Montelatici E, Crisan M, Corselli M, Huard J, Lazzari L, Peault B: Perivascular multi-lineage progenitor cells in human organs: regenerative units, cytokine sources or both? Cytokine Growth Factor Rev 2009;20: 429-434.

-27 Crisan M, Chen CW, Corselli M, Andriolo G, Lazzari L, Peault B: Perivascular mulipotent progenitor cells in human organs. Ann NY Acad Sci 2009;1176:118-123.

28 Diaz-Flores L, Gutierrez R, Madrid JF, Varela H, Valladares F, Acosta E, Martin-Vassallo P, Diaz-Flores L Jr: Pericytes. Morphofunction, interactions and pathology in a quiescent and activated mesenchymal cell niche. Histol Histopathol 2009;24:909-969.

29 Ozerdem U, Grako KA, Dahlin-Huppe K, Monosov E, Stallcup WB: NG2 proteoglycan is expressed by mural cells during vascular morphogenesis. Dev Dyn 2001;222:218-227.

30 Verbeek MM, Otte-Holler I, Wesseling P, Ruiter DJ, de Waal RMW: Induction of $\alpha$ smooth muscle actin expression in cultured human brain pericytes by transforming growth factor- $\beta 1$. Am J Pathol 1994; 144: 372-382.

- 31 Song S, Ewald AJ, Stallcup W, Werb Z, Bergers G: PDGFR $\beta+$ perivascular progenitor cells in tumors regulate pericyte differentiation and vascular survival. Nat Cell Biol 2005;7:870-879.

32 Song N, Huang Y, Shi H, Yuan S, Ding Y, Song X, Fu Y, Luo Y: Overexpression of platelet-derived growth factor-BB increases tumor pericyte content via stromal-derived factor- $1 \alpha$ CXCR 4 axis. Cancer Res 2009;69: 6057-6064.

-33 Bergers G, Song S, Meyer-Morse N, Bergsland E, Hanahan D: Benefits of targeting both pericytes and endothelial cells in the tumor vasculature with kinase inhibitors. J Clin Invest 2003;111:1287-1295.

34 Greenberg JI, Cheresh DA: VEGF as an inhibitor of tumor vessel maturation: implications for cancer therapy. Expert Opin Biol Ther 2009;9:1347-1356. 
35 Helfrich I, Scheffrahn I, Bartling S, Weis J, von Felbert V, Middleton M, Kato M, Ergun $\mathrm{S}$, Schadendorf D: Resistance to antiangiogenic therapy is directed by vascular phenotype, vessel stabilization, and maturation in malignant melanoma. J Exp Med 2010;207: 491-503.

36 Hellberg C, Ostman A, Heldin CH: PDGF and vessel maturation. Recent Results Cancer Res 2010;180:103-114.

37 Ozerdem U: Targeting of pericytes diminishes neovascularization and lymphangiogenesis in prostate cancer. Prostate 2006;66: 294-304.

38 Livanainen E, Lauttia S, Zhang N, Tvorogov D, Kulmala J, Grenman R, Salven P, Elenius $\mathrm{K}$ : The EGFR inhibitor gefitinib suppresses recruitment of pericytes and bone marrowderived perivascular cells into tumor vessels. Microvasc Res 2009;78:278-285.
39 Vartanian RK, Weidner N: Endothelial cell proliferation in prostatic carcinoma and prostatic hyperplasia: correlation with Gleason's score, microvessel density and epithelial cell proliferation. Lab Invest 1995;73: 844-850.

40 Seigal JA, Brawer MK: Topography of neovascularity in human prostate carcinoma. Cancer 1995; 75:2545-2551.

41 Hanahan D, Folkman J: Patterns and emerging mechanisms of the angiogenic switch during tumorigenesis. Cell 1996;86:353364.

42 Bergers G, Benjamin LE: Tumorigenesis and the angiogenic switch. Nat Rev Cancer 2003; 3:401-410.

43 Soares AB, Juliano PB, Araujo VC, Metze K, Altemani A: Angiogenic switch during tumor progression of carcinoma ex-pleomorphic adenoma. Virchows Arch 2007;451:6571.

44 Morikawa S, Baluk P, Kaidoh T, Haskell A, Jain RK, McDonald DM: Abnormalities in pericytes on blood vessels and endothelial sprouts in tumors. Am J Pathol 2002;160: 985-1000.
45 Gerhardt H, Betsholtz C: Endothelial-pericyte interactions in angiogenesis. Cell Tissue Res 2003;314:15-23.

46 Guillemin GJ, Brew BJ: Microglia, macrophages, perivascular macrophages, and pericytes: a review of function and identification. J Leukocyte Biol 2004;75:388-397.

47 Kruger M, Bechmann I: CNS pericytes: concepts, misconceptions, and a way out. Glia 2010;58:1-10.

48 Schlingemann RO, Rietveld FJR, de Waal RMW, Ferrone S, Ruiter DJ: Expression of the high molendothelial cellular weight melanoma-associated antigen by pericytes during angiogenesis in tumors and in healing wounds. Am J Pathol 1990;136:1393-1405.

49 Orlidge A, D'Amore PA: Inhibition of capillary endothelial cell growth by pericytes and smooth muscle cells. J Cell Biol 1987;105: 1455-1462. 